\title{
Cross-cultural Variations of the HIV/AIDS IS DEATH Pictorial Metaphor
}

\author{
Magonya Achieng' Lilian
}

Department of Linguistics, Maseno University, Kenya

Copyright $₫ 2017$ by authors, all rights reserved. Authors agree that this article remains permanently open access under the terms of the Creative Commons Attribution License 4.0 International License

\begin{abstract}
For three decades now, HIV/AIDS undeniably remains one of the leading killer diseases in Sub-Saharan Africa. The same narrative is advanced in the literature by sociologists and epidemiologists where mental images that cognitively represent a true African embodied experience with HIV /AIDS is death and its respective personifications such as HIV/AIDS IS A SNAKE, HIV/AIDS IS A WALKING CORPSE and HIV/AIDS IS GRIM REAPER (cf. Sabatier, 1987, Sontag, 1988, De Waal, 2006 and Magonya, 2012). From the foregoing, it can be said that linguistic studies on cross-cultural variations of the HIV/AIDS IS DEATH pictorial metaphor in posters are relatively few in cognitive linguistics. Furthermore, there is need to undertake scientific investigations on how mental images are psychologically and metaphorically linked to the embodied experience with the pandemic. In this regard, the two fold objectives of this paper are: First and foremost, to study the cross-domain mappings of the HIV/AIDS IS DEATH pictorial metaphors and second to investigate cross-cultural variations of the aforementioned pictorial metaphor. The conceptual framework guiding the study espouses arguments from Lakoff and Johnson (1980) and Lakoff and Turner (1989) on the conceptual metaphor theory (CMT), with specific focus on death metaphors outlined in More than cool reason. A field guide to poetic metaphor, together with Kövesces (2010) arguments on metaphor and variation. The study will employ an analytic research design and data will be collected from 11 purposively sampled websites where a total of 20 posters coined around HIV/AIDS IS DEATH pictorial metaphor were drawn. Using content analysis, data collected from online sources was coded, arranged into themes and analyzed qualitatively. The findings for the study are consistent with Kövesces thesis on the existence of cross-cultural variations in HIV/AIDS IS DEATH conceptual metaphor.
\end{abstract}

Keywords HIV/AIDS, Death Metaphors, Cognition

\section{Introduction}

Cognitive linguists subscribe to the thesis that human cognition unconsciously processes metaphorical utterances because of our embodied experience with concepts. Seemingly, this school of thought was belittled by earlier language philosophers who subscribed to the view that metaphors do not warrant any scholarly attention (Lakoff, 1980; Moreno, 1998, Lakoff, 2008). In fact, Lakoff and Turner (1989) opine that various concepts ranging from emotions, society, human character and even the nature of life and death among other things are understood and expressed metaphorically. Apparently this also extends to eco-disasters and even life threatening ailments that record high mortality rates such as HIV/AIDS, cancer and any other pestilences. The aforementioned ailments can be expressed metaphorically to paint a grim picture of man's experience with such dreaded disasters (cf. Sontag, 1989, Byock, 2002, Moore \& Williamson, 2003 and Wang, 2009). Taking the case of HIV/AIDS whose metaphors are of key interest in this paper, it is arguable that HIV/AIDS coexists with the following pejorative terms such as plague, calamity, epidemic and disaster. Moreover, for Sontag (1988:17) HIV/AIDS has dual metaphoricity. Said differently, the asymptomatic nature of HIV/AIDS is construed to be cancer-like, whereas its mode of transmission invokes the sense of pollution or contagion realized in expressions such as, one can contact HIV/AIDS through contaminated blood or bodily fluids of a seropositive person. Closely related to the issue of contagion is Moore and Williamson (2003) thesis that sex can be a corrupting agent ${ }^{1}$ and sexual acts allow filth to infiltrate the human body. Thus, HIV/AIDS reinforces the link between sex and death. Besides this, literature on HIV/AIDS by scholars such as Moore and Williamson, (2003) affirm that dissociating HIV/AIDS from death, fear

1 Moore and Williamson (2003:8) cite three Platonian laws that morally corrupt the human body namely drink food and reproduction. With regard to sexuality, just like death, sex is regarded a taboo topic and various cultures have norms on sexuality because of the intricate link between sex and death. In Moore's and Williamson's perspective, the bodily excess is associated with ailments and death 
and sexuality is baseless. In fact, for Byock, (2002), Fernández (2006) and Gire (2014), the fear of death is universal $^{2}$. Byock (2002) and Fernández (2006) further stress that death is actually a fear-based taboo word with psychological, social and religious affiliations. Besides this, the multifaceted dimension of the fear of death entails fear of the dying process, premature death, loss of a loved one, the decaying corpse, evil spirits, premature death, phobic fear of death and fear of afterlife experiences. From the foregoing, it is the mystical nature of death that makes people resort to using metaphors and euphemisms in reference to it. Psychologists such as Gire (2014) contend that the fear of death is premised in the terror management theory which holds that human beings and animals are instinctively preconditioned to uphold self-preservation at all costs. Naturally, this explains how animals instinctively flee from life threatening scenarios. Gire further argues that man's sophisticated cognitive abilities enable him to effortlessly process the outcomes of mortality, and consequently, trigger positive or negative death anxieties ${ }^{3}$. On the positive side, people who fear death strive to stay alive, whereas the negative side of death would make others either engages in risky activities such as sky diving, taking a job as an undertaker, a morgue attendant or even avoids scenarios where death has occurred as death aversion strategies. In the context of societal death anxieties, Gire dichotomizes such societies into two parts notably death denying cultures and death affirming cultures. Examples of death denying cultures are Western nations where higher death anxieties are recorded due to death- related phobias. Whereas, both Eastern and African nations are classified under death-affirming cultures, since death in such regions is not only culturally accepted, but is equally perceived as a positive transition to the afterlife. Moreover in such contexts, the death anxiety level is relatively lower than in the Western countries. It is in this regard, that this paper examines death metaphors used in HIV/AIDS campaign posters. To able to undertake such a study, a re-examination Turner's and Lakoff's (1989) conceptual metaphors of life, death and time is imperative as seen in Appendix 1. A number of scholars

\footnotetext{
2 Moore and Williamson (2003) and Gire (2014) argue that the fear of death is almost universal, it is innate. Further, aspects such as religion has to some extent mitigated the fear of death in contemporary times. However, the constant fear of annihilation cannot wished away (cf. Byock, 2002:279), as humanity still registers fear and trauma, especially, in contexts recording high mortality rates as seen in terror attack on the Pentagon on the $11^{\text {th }}$ of September 2011 and bird flu on several nations. Seemingly, this extends to even fear of life threatening terminal illnesses.

3 Gire provides examples of studies showing inconsistencies in death anxieties, he cites Duff and Hugg's (1995) research where higher levels of death anxiety was recorded among christians, where the converse was expected, where religion is supposed to psychologically prepare one for the afterlife. Besides this case, Gire cites Morris and Mc Adie (2009) study which compared Muslims, Christians and non-religious groups. Christians recorded lower death anxiety than both Muslims and non-religious groups. The Christians perceived death as a reward for good living, (cf. Fernàndez, 2006) whereas Muslim remained doubtful whether they were good Muslims, thus they were uncertain of their ultimate fate either in heaven or hell. This pointed out that it was the anticipation of a reward for good living in the afterlife rather than the mere belief or religiosity that lowered death anxieties among Christians.
}

such as Lakoff and Turner (1989), Wang, (2009), Al Meshhedany and Al-Sammerai (2010) and Trinity University (2016) concur that life, death and time are intertwined. Said differently, human beings are actually living on borrowed time. Once time is up, we succumb to the inevitable jaws of death (Lakoff \& Turner, 1989; Fernández, 2007; Nyakoe, Matu and Ongarora, 2012; Golzadeh \& Pourebrahim and Gire, 2014). In Fernández's (2006, 2007), Psomadakis (2007) and Al-Meshhedany \& Al-Sammerai (2010) perspective death picks up from where life ends via the DEATH IS A JOURNEY metaphor where their myriad destinations such as hell, purgatory or heaven. Moreover, $\mathrm{Al}$ Meshdany and Al-Sammerai (2010) base their arguments on the Quran, they hold the thesis that dying corresponds to living, and the dead embark on a journey in the afterlife which can either be destined towards heaven or hell. Al-Meshhedany and Al-Sammerai (2010:12) further contend that

For a Muslim, death is an obligatory transitional element between the life before death and the life after death. So the definition of death for a Muslim would be absolute disappearance of the functions for the time period between the two lives-one before death and another after death.

Contrary to Islam, Gire (2014) cites the case of reincarnation in Buddhism where there are numerous exits and entries in life with man being reborn with a new identity. Hence in Buddhism, a vicious circle governs life and death. From the foregoing, this brings on board a few English words explaining the aforementioned concepts, for instance the afterlife, life after death, eternal life or even the living dead, which allude to the continuity of life even after death. Such views are also consistent with other views on the same in Judeo- Christian beliefs, indigenous African ideologies and Native American tribes as stated by Fernández (2006), Gire (2014) and Baloyi and Makobe-Rabothata (2014: 154)

When people die, they transcend to the spirit world to be in the company of the living dead or ancestors...there is therefore a continuous and unbreakable communication and connectedness between the living and living dead. For the traditional African religion the deceased is believed to be living in the ontology of the invisible intangible beings....

To clearly demonstrate this line of thought on the interlaced relation of life and death, Wang's (2009:44) paper on Ingmar Bergman's Appropriations of images of Death in the Seventh Seal movie, presents the case of a Knight called Antonius Block who returns from a crusade during the Bubonic plague, he engages in the following interesting conversation with death, where Block further challenges death in a game of chess so as to buy time and delay his death. Here, chess epitomizes STAYING ALIVE IS A CONTEST conceptual metaphor where Block has to now fight for his life at all costs. 
Block says: Who are you?

Death replies: I am death.

Block counters: Have you come for me?

Death affirms: I have walked by your side

"So I have noticed" Block acknowledges with a grim humor (Wang, 2009:44)

From this dialogue, Wang adds that life and death are two sides of the same coin and this is evident in another example used by Wang, where he draws from the story titled THREE QUICK AND THREE DEAD, where three noble men who come from a pleasure outing enter a cemetery, only to find three dead corpses stand as if they are waiting for their arrival. The corpses utter the following words "As you are now, so once were we. As we are now so will you be”. Besides this, even in Islam, Al-Meshhedany and Al Sammerai (2010: 12) say that the life, time, death continuum exist in the Quran where Allah as man's creator determines his lifespan and time of death. Therefore, in Moore and Willamson (2003), Fernàndez (2006), Wang (2009), Al-Meshhedany and Al-Sammerai (2010), Golzadeh and Pourebrahim (2013) perspective, death is an inevitable part of the human life cycle and the role of time in the life and death equation is neatly summed up in Trinity University (2016: 8) as follows...Grains of sand/ Hour glass is a familiar reference to time, to life and to death. The force of this image attests to the fact that life in its rudimentary expression is time: death simply means that time has run out. Nonetheless, in Lakoff and Turner's perspective, time plays a causal role in the occurrence of events including death and serves as a metaphorical change causing agent under EVENTS ARE ACTIONS conceptual metaphor.

From the above discussions, it becomes imperative to examine the list of basic metaphors of life, death and time (see Appendix 1), which will enable us analyze death pictorial metaphors in section 4.0.

Besides the outlined conceptual metaphors death in Appendix 1, there are also metonymies of death as stated by Fernández (2007:13) such as THE SENTIMENTAL EFFECTS OF DEATH STAND FOR DEATH and THE PHYSIOLOGICAL EFFECTS OF DEATH STAND FOR DEATH as captured respectively in the following examples Cut away, almost in the bloom of life...death has created a melancholy void to her husband, her children and many affectionate relations and The release from all earthly pain and suffering. Such metonymies, echo Lakoff and Turner's thoughts that the way we feel about death will be conceptually manifested in expressions and mental images associated with death. This line of thought is consistent with the personifications of death as outlined by Wang (2009) and Golzadeh and Pourebrahim (2013). Further, there are images or personifications of death as an ontological metaphor which have been listed by Lakoff and Turner (1989), Wang (2009) and Golzadeh \& Pourebrahim (2013) include amber beads, dance of death, sickle, scythe, sword, hour glass, withering of flowers, skeletons, skulls, rotten corpses, animals such as the owl, images of the final places of sleep such has the graveyard, stillness, darkness, silence, isolation, of release of peace as may she or he rest in eternal peace, grim reaper, a beast among others. It is such pictorial metaphors which will be investigated on in the HIV/AIDS campaign posters.

\section{Metaphor and Variation}

This paper is based on metaphorical cross-cultural variations and it draws insights from Zoltan Kövesces on the potential causes of metaphorical variation. Kövesces (2005) holds the thesis that metaphor, culture and cognition are intertwined. He draws examples from certain near universal generic metaphors such as ANGER IS A HEATED FLUID IN A CONTAINER or HAPPINESS IS LIGHT which exist in Chinese, Hungarian, Zulu and Wolof. The listed metaphors serve as evidence that dissimilar cultures can experience similar bodily experiences in their conceptualizations of either anger or happiness. Despite this, there are cross-cultural variations in the conceptualizations of the same metaphors, for instance Japanese and Dholuo ${ }^{4}$, have ANGER IS IN THE BELLY conceptual metaphor, in Dholuo, one can say, Iya no wang' (My stomach burnt), where the belly as a container gets "burnt" as a result of holding the heated fluid (anger) (cf. Magonya and Oloo, 2015), further among the Zulu, ANGER IS IN THE HEART metaphor serves as the equivalent of ANGER IS A HEATED FLUID IN A CONTAINER, where the heart and not the belly is viewed as a container of emotions. From the foregoing, Kövesces offers the following pointers on the emergence of metaphorical variations.

(a) Universal experiences do not lead to universal metaphors.

(b) Bodily experience may be selectively used in certain metaphors as seen in previous examples

(c) Bodily experience may be overridden by both culture and cognition.

(d) Primary metaphors are not necessarily universal.

(e) Complex metaphors may be potentially or partially universal.

(f) Metaphors are not necessarily based on bodily experience but on cultural considerations.

From the above pointers, Kövesces (2005) further argues that there are various reasons for cross-cultural variations in metaphors which he labels congruent metaphors and alternative metaphor. Alternative metaphors are further subdivided into alternative conceptualizations, range of the target domain, scope of the source domain, preferential conceptualizations and unique metaphors. First and foremost, under congruent metaphors, cultures can have near universal

4 Dholuo is a Nilotic language spoken in Kenya and Uganda. 
experiences with certain phenomena such as deaths in the generic level as in the case of DEATH IS A JOURNEY, DEATH IS DARKNESS, DEATH IS A BATTLE or DEATH IS REST. However, variations occur at the specific level where different cultures design their own conceptualizations of death as in the case of DEATH IS CHARON THE FERRYMAN in the Greek culture, while its English counterpart is DEATH IS GRIM REAPER. For the case of alternative metaphors, various kinds exist, first there are alternative conceptualizations whereby a language can have a different source domain for the same target domain in another language, a case in point is SOLUTION IS A PUZZLE metaphor in English, realized in the linguistic metaphor I have found the solution to my problem. To Iranians, the source domain associated with the same metaphor would be a chemical solution and not a puzzle. Second, range of the target domain presents differences in the range of conceptual metaphors, and suggests that there can be cultural differences in the range of source domains as shown in the case of ANGER IS A HEATED FLUID IN A CONTAINER is a near universal metaphor, yet other cultures perceive anger as either as being in the heart or the belly as seen among the Zulu and Dholuo or Chinese speakers. Third, preferential conceptualization suggests that two cultures may have the same conceptual metaphors for a given target domain, but speakers might prefer different sets for instance Christians might view DEATH IS A JOURNEY TOWARDS ONES MARKER or HEAVEN, while an atheist might simply view it as DEATH IS SLEEP because of they do not believe in God. Finally, unique metaphors are used in culturally peculiar ways as in the case of DEATH IS A CAMEL DRIVER in the Arabian culture as cited by Meshihedany and Al -Sammerai (2010), which apparently is the variant of DEATH IS A COACHMAN in the English language. From the outlined types of cross -cultural metaphors, this paper will particularly focus on congruent metaphors, range of the target domain, preferential conceptualizations and unique metaphors. Further, variations of HIV/AIDS IS DEATH pictorial metaphors will be explained in 2.1.

\subsection{Variation on Death Metaphors}

Literatures on metaphors of death confirm the existence of cross-cultural variations. According to Golzadeh and Pourebrahim (2010) study on death metaphor in the Quran and Nahjul Balagha respectively as religious texts, they observe that existence of LIFE IS A JOURNEY, DEATH IS A BATTLE/DEATH IS WAR, DEATH IS AN OPPONENT, DEATH IS DEPARTURE/DEATH IS A STAGE OF JOURNEY, DEATH IS HUMAN, DEATH IS SLEEP/REST, DEATH IS A CALLER, DEATH IS A CAMEL DRIVER, DEATH IS A SEEKER, DEATH IS A CAPTOR, DEATH IS UNINVITED GUEST, DEATH IS A GUILTY ONE, DEATH IS A KILLER (DEATH IS A BEAST, DEATH IS A DESTRUCTIVE ARROW), DEATH
IS SOMETHING RED, POWER IS UP AND WEAKNESS IS DOWN. From the outlined list of metaphors, there are some slight cultural variations with certain metaphors such as LIFE IS A JOURNEY, DEATH IS HUMAN, DEATH IS A CALLER, DEATH IS A CAMEL DRIVER, DEATH IS A CAPTOR, DEATH IS UNINVITED GUEST, DEATH IS A GUILTY ONE, DEATH IS A DESTRUCTIVE ARROW, AND POWER IS UP AND WEAKNESS IS DOWN. To begin with, LIFE IS A JOURNEY seems to vary with Lakoff's and Turner's (1989) thesis, in the sense that within religious circles whether in Islam or Christianity, there are two kinds of life, the good life is premised on morals, and immorality. There are two paths in life's journey, the straight and crooked paths, there are also two kinds of travellers notably the righteous ones and the wicked ones and further there are two possible destinations to the afterlife either heaven or hell (cf. Psomadakis, 2007; Al Meshihedany and Al Sammerai, 2010: 12), this means that alternative conceptualizations on how religious and unreligious people lead their earthly lives is guided by alternative variations. In relation to DEATH IS HUMAN metaphor which is case of personification meaning that it is actually an ontological metaphor, whereby human qualities are assigned non-human entities under the EVENTS ARE ACTIONS or INANIMATE PHENOMENA ARE HUMAN AGENTS (cf. Psomadakis, 2007:227, Kövesces, 2010:39), DEATH IS HUMAN metaphor is a variant of DEATH IS GRIM REAPER/ANGEL OF DEATH (Malak al maut) ${ }^{5}$ who harvests human souls as captured in the following Go forward and meet death and don't wait for its arrival (Sermon 254:n221 Meshihedany and Al Sammerai , 2010: 72). Contrastively, Psomadakis (2007) presents a variant image of Grim reaper in Ancient Greek as Charon the ferryman, who brings the deceased to the house of Hades in the underworld. Further, in Meshihedany and Al Sammerai's work, they also present the emotive part of death as DEATH IS A GUILTY ONE conceptual metaphor as expressed in the linguistic metaphor it is the guilty one which leaves on trace of itself, never pays its indemnity of its guilt (Sermon:133:96).From this angle, metaphors such as DEATH IS A SEEKER, DEATH IS A CAPTOR or DEATH IS AN UNINVITED GUEST, would equate death to a thief that harvests human souls as shown in the following linguistic metaphors Death is a seeker that is a finder, It warps the cords of its trap round your legs (Sermon 289:253) and Death is a morose and severe guest (Sermon: 289:253) in Meshihedany and Al Sammerai 2010.

The case of DEATH IS CALLER/SUMMONER as in the linguist metaphor Death as knocked his door, is also evident in Judeo Christian beliefs. Moreover, Nyakoe, Ongarora and Matu (2012) illustrate this in Ekegusii, a Bantu language

5 Al-Meshhedany and Al Sammerai (2010:12) argue that in Islam whenever a person dies, the angel of death (Malak al maut) sits on the head of a dead person and re-examines how the person led his life while on earth, whereby evil souls face God's wrath and good souls remain under God's mercy and providence. 
spoken in Kenya, where there is a euphemism for the aforementioned metaphor as in karangeriwa na omonene meaning to be called or summoned by God. Further, there exists DEATH IS A CAMEL DRIVER metaphor, which serves like the variant of DEATH IS A COACHMAN in Lakoff and Turner (1989). According to Meshihedany and Al-Sammerai (2010), in the Arabian culture, a camel driver is normally the leader of the caravan and he determines the destination of any journey. Likewise, metaphorically death also provides options for ones journey either towards ones marker or hell. For the case of DEATH IS A DESTRUCTIVE ARROW, the destructive arrow metonymically represents a killer's execution weapon, which serves more or less a similar function as Grim reaper's scythe. Therefore, variations can be seen in the execution styles of death and it can be deduced that the DEATH IS HUMAN metaphor is clearly a case of a congruent variation, where the said metaphor is at the generic level, whereas DEATH IS A CAMEL DRIVER and DEATH IS AN UNINVITED GUEST are at the specific level

Ferdinárd (2006) also presents other metaphors of death from the Christian perspective, notably DEATH IS A JOYFUL LIFE. LIFE IS MISERY and DEATH IS REWARD are evidence of the range of the target domain. On one hand, DEATH IS A JOYFUL LIFE whereby Christians believe that the deceased will live in eternal glory in Heaven as expressed in lexical terms such as abode of peace, or joyful expectation of the resurrection of the just. DEATH IS REWARD and LIFE IS MISERY are variants of Lakoff's and Turner's LIFE IS A BONDAGE metaphor. Said differently, DEATH IS REWARD metaphor considers death as a kind of liberation from life's tribulations, where the deceased will find hope and consolation in the afterlife, especially if he or she lived a virtuous life. In the same vein, LIFE IS MISERY construes life as riddled problems as shown in the following example in an Irish Obituary analyzed by Fernández (2006:119)

...In the pious and firmly grounded hope that their darling has gone to eternal rest-and that in the fullness of time, when it shall please God to call there from that scene of wretchedness, they will join her in that abode of peace.

Here, Fernández singles out eternal rest and abode of peace as the rewards of eternal rest in the afterlife, whereas the scene of wretchedness evokes life's miseries that only death can liberate man from. From the above literature, we have attempted to explore the various cross-cultural variations of death metaphors, and the same issue will be revised in section 4 .

\section{Methodology}

This section describes the methodology designed for research. The study is premised on an analytical design. Data was purposively sampled from 11 websites which had 20 posters bearing the HIV/AIDS IS DEATH pictorial metaphor as listed in Table 1. Data collection involved browsing online for relevant websites which had the required metaphor. The websites and number of posters are indicated in Table 1.

Table 1. Websites for HIV/AIDS is Death Pictorial Metaphors

\begin{tabular}{|c|c|}
\hline Website & $\begin{array}{c}\text { Number } \\
\text { of } \\
\text { Posters }\end{array}$ \\
\hline http://www.graphicintervention.com & 8 \\
\hline http://www.aep.librochester.edu & 2 \\
\hline http://www.smithsonianmag.com & 1 \\
\hline http://www.m.nih.gov/exhibition/visualculture/target.html & 1 \\
\hline http://www.condomunity.com & 1 \\
\hline http://www.pinterest.com & 1 \\
\hline http://www.carnaxe.com & 1 \\
\hline http://www.dpvintageposters.com & 1 \\
\hline http://www.celebrity.com & 1 \\
\hline http://www.mukuyu.wordpress.com & 1 \\
\hline http://www.m-mc.org/mmc & 2 \\
\hline TOTAL & 20 \\
\hline
\end{tabular}

Further, the 20 posters were subsequently organized into themes such as HIV/AIDS IS A FEROCIOUS BEAST MONSTER, HIV/AIDS IS VENOMOUS SNAKE, HIV/AIDS IS A LOOMING KILLER SHARK, HIV/AIDS IS THE BIG BAD WOLF, HIV/AIDS IS A BAD OMEN, HIV/AIDS IS DEATH PERSONIFIED, HIV/AIDS IS GRIM REAPER, DYING FROM HIV/AIDS IS ETERNAL SLEEP, DYING FROM AIDS IS A DEPARTURE TOWARDS ONES FINAL DESTINATION, HIV/ AIDS IS SILENCE, BEING SEROPOSITIVE IS LIVING ON BORROWED TIME, HIV/AIDS IS DEATH and DARKNESS IS DEATH. Data was analyzed qualitatively and a summary of the findings is presented in section 4 .

\section{HIV/AIDS is a Ferocious Monster/Beast}

Lakoff and Turner (1989) hold the thesis that death can be personified in the image of a beast that devours mankind, in the following section, pictorial metaphors using images of the sphinx, monstrous snakes, wolves and sharks will be examined.

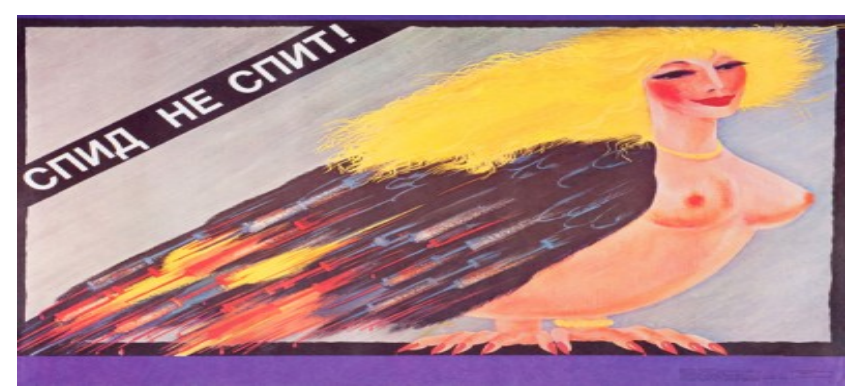

Source: http//www.graphicintervention.com

Poster 1. 1990 AIDS DOES NOT SLEEP! Russian AIDS poster 
This poster was used to sensitize Russian citizens on the dangers of HIV /AIDS, using the message AIDS does not sleep!. Here, the pictorial metaphor of HIV /AIDS as a ferocious monster is portrayed using the image of the Sphinx. According to Sherman (2008) and Roman and Roman (2010), there is a male sphinx in the Egyptian mythology and a female sphinx in the Greek mythology. On one hand, the Egyptian sphinx is a male-headed winged lion that represents pharaoh or the sun god. On the other hand, the Greek sphinx is a female hybrid monster that is a woman-headed winged lion having a snake's tail. The Greek sphinx is also labelled the destroyer, for she devoured any person who failed to solve her riddles. However, Oedipus is cited as the only person who solved her riddle and as a result of this she committed suicide. Our thesis is that probably the hybrid nature of the female sphinx metaphorically represents the asymptomatic nature of HIV/AIDS, as manifested in various ailments such as tuberculosis, malaria, pneumonia and herpes. The poster sells its message on the epidemic using HIV/AIDS IS A FEROCIOUS FEMALE SPHINX THAT IS READY TO DEVOUR MANKIND conceptual metaphor.

\subsection{HIV /AIDS is a Ferocious Snake}

According to Sherman (2008), Anjomshoa and Sadighi (2015) the cultural conceptualizations of snakes are dynamic since snakes have a ray of positive and negative attributes ranging from being regarded as deities ${ }^{6}$, possessing healing powers, ancestral spirits, cunning, treacherous, intelligent, fertility, patience, rejuvenating, seductiveness and poison. However, as observed by Sherman (2008) in contemporary times, snakes are associated with evil especially with reference to Judeo Christian beliefs on the fall of man in the Garden of Eden. In a number of HIV/AIDS posters, the snake pictorial metaphors appear to be near universal at the generic level, whereas at the specific level, there are variations as discussed below. In Poster 2, HIV/AIDS is either perceived as follows. HIV/AIDS IS A MONSTROUS PYTHON WITH ITS FANGS READY TO STRIKE OR HIV/AIDS IS A LETHAL SNAKE BITE IN AN AMOROUS ENCOUNTER as expressed linguistic expressions respectively in the Kenyan AIDS poster stating Comrade, would you put your penis here...I abstain and in the Netherlands AIDS poster(Poster 3) stating AIDS is the killing bite of love, where the male genitalia metonymically represents a seropositive person who can readily transmit HIV/AIDS to a HIV negative person. Here, HIV is perceived as a lethal venom which infiltrates the human body through unprotected sex that is metonymically represented by the male genitalia having the head of a snake. In the Kenyan poster (Poster 2), the monstrous python is a beast that will devour a person.

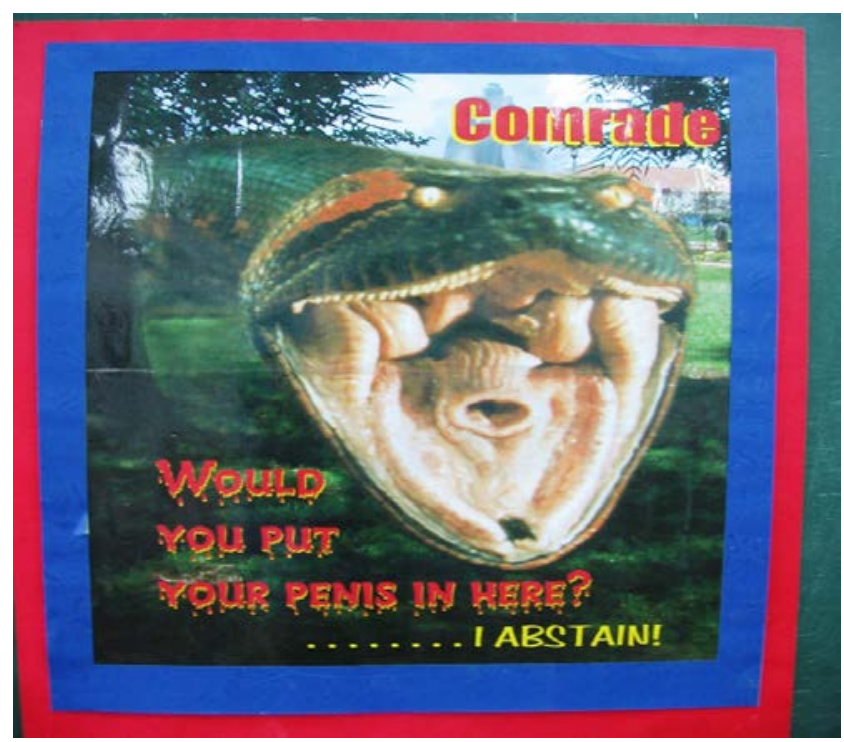

Source: http:www.mukuyu. wordpress.com

Poster 2. Kenyan AIDS poster

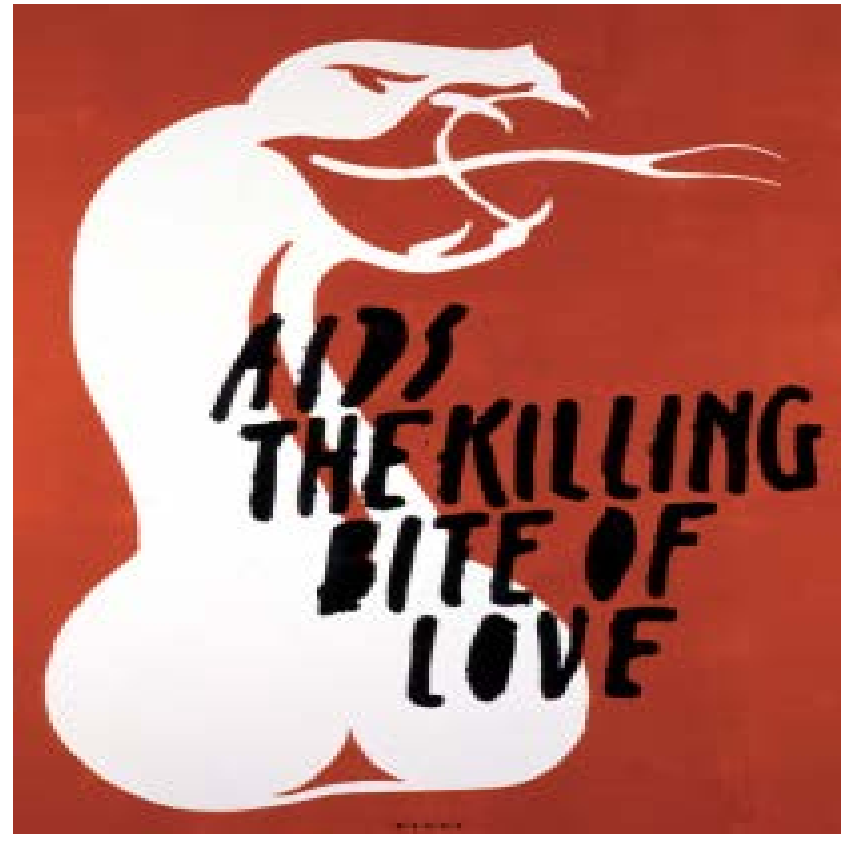

Source: http//www.graphicintervention.org

Poster 3. (1993) Netherlands AIDS poster
6 According to Sherman (2008) The Greek god of medicine called Ascelpious is depicted as holding the caduceus which is a staff having two intertwined serpents coined around it. Legend has it that he discovered medicine after watching serpents use herbs to resurrect other snakes. The Egyptians worshipped Renenulet, a cobra goddess who protected children and pharaoh. Egyptians also idolized Nehebkau a snake deity who guarded the entrance of the underworld. The Aborigines believe in Wollunqua a rainbow snake that is connected to both the rainbow and creation. Whereas in Judeo-Christian beliefs, snakes represent evil which has to be eradicated. 


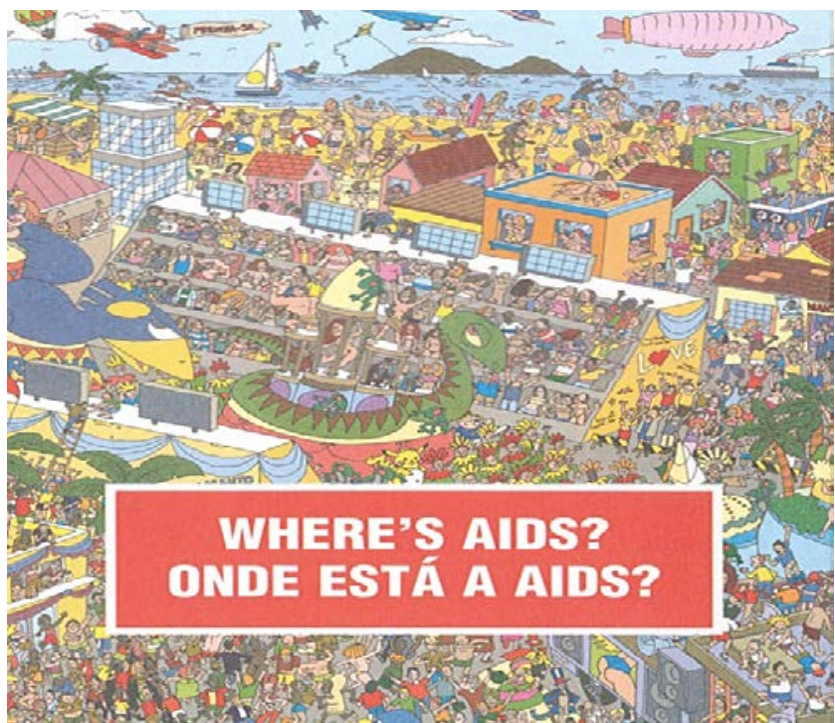

Source: http://carnaxe.com./br/vacina-aids

Poster 4. Brazillian AIDS poster

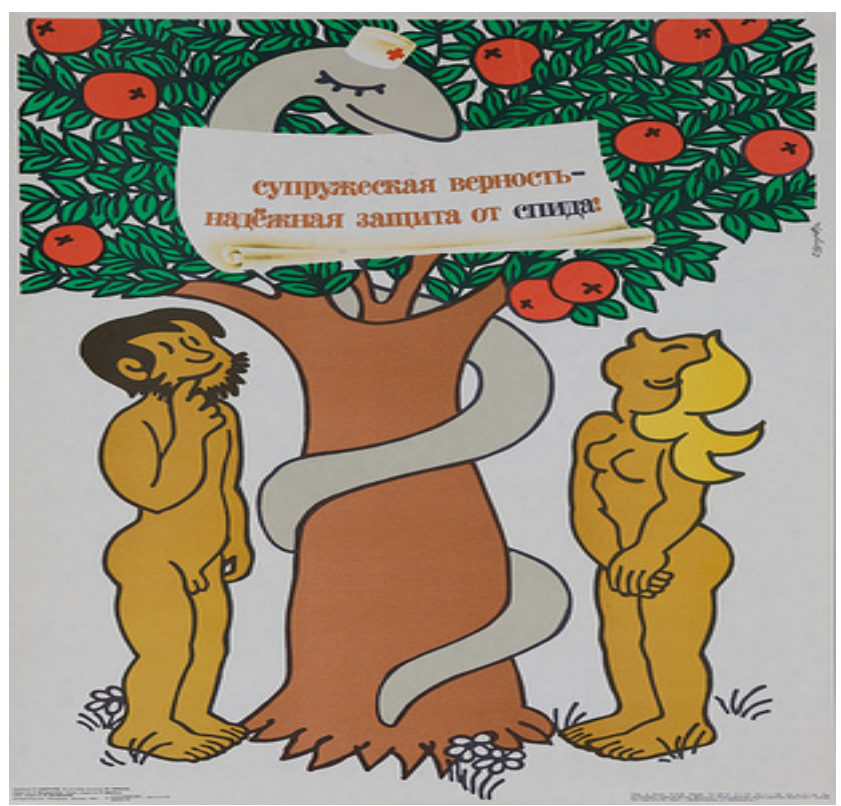

Source: http://www.dpvintageposters.com/cgi-localDetail.cgi?d=7647 Poster 5. 1990 Russian AIDS poster

Whereas in the Brazillian poster (Poster 4), asking the question Where's is AIDS?, uses the snake in the grass idiom under HIV/AIDS IS THE HIDDEN LETHAL ENEMY conceptual metaphor. Here, HIV is the undetected silent killer which strikes unsuspecting persons who are busy pursuing the pleasures of life as metonymically presented by the carnival mood in Poster 4.Contrastively, in Poster 5 has Russian placard held by a snake's fangs which reads Matrimonial fidelity is the best protection against AIDS. The poster focuses on the fall of man in the Garden of Eden, where PEOPLE ARE PLANTS metaphor is used in the tree of life pictorial metaphor. Further, the temptation surrounding sexuality is represented by the fruits in the tree that are being eyed by both Adam and Eve, whereas their nudity metonymically represents the vulnerability of humanity in the light of the epidemic, with the snake representing the killer disease. In this context, the snake has a nurse's white cap to symbolize its healing powers. Put differently, fidelity in marriage is the surest mode of prevention against HIV/AIDS. The virus is represented by the huge snake as captured by HIV/AIDS IS A VENOMOUS GIGANTIC SNAKE WHICH CAN BE AVOIDED BY UPHOLDING FIDELITY IN MATRIMONY conceptual metaphor. In the Kenyan AIDS poster coined in Kiswahili which reads Ikiwa UKIMWI haikutishi wewe, hebu fikiria vile UKIMWI inaweza kumdhuru mtoto wako, hebu fikiria (if AIDS does not scare you, just think about how AIDS can affect your child, just think about). Contrary to other pictorial metaphors that employed images of gigantic snakes in reference to HIV/AIDS, the Kenyan poster (Poster 6) employs the image of a black mamba which is equally a poisonous serpent capable of killing its prey instantly. The black mamba has already encircled a child and has its fangs ready to strike the child. Here, behavior change communicators are using the HIV/AIDS IS A LETHAL BLACK MAMBA conceptual metaphor.

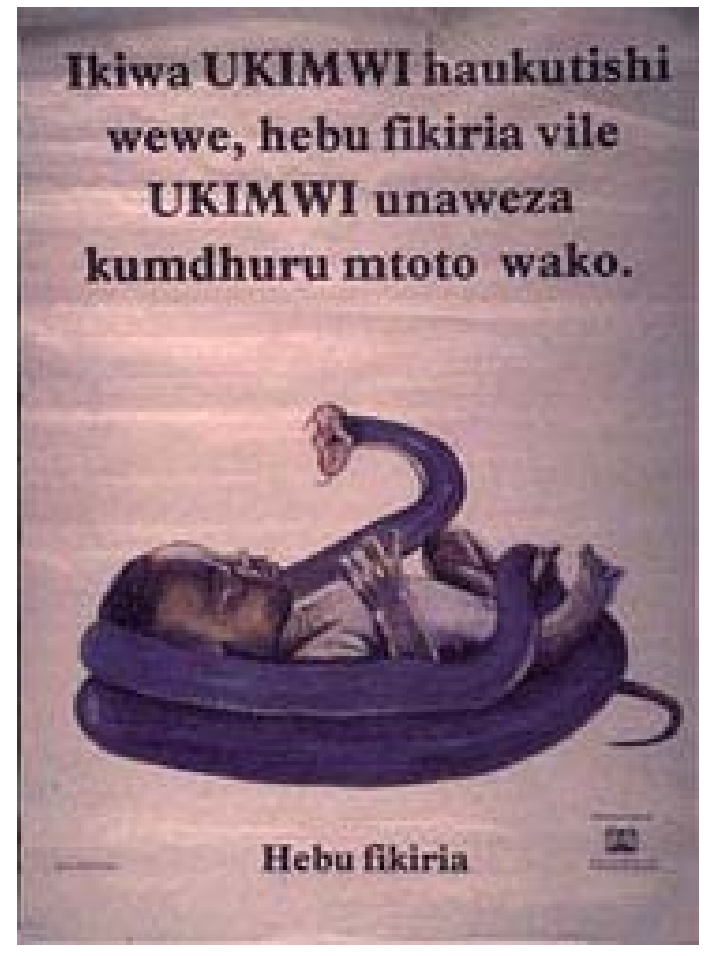

Source: http://www.aep.rochester.edu/node/43824

Poster 6. 1993 Kenyan AIDS poster

\subsection{HIV/AIDS is a Shark and HIV/AIDS is the Big Black Wolf}

Besides the snake, and sphinx, other vicious animals such as sharks sand wolves have been used in unique ways in AIDS posters Denmark and Italy as in Posters 7 and 8 respectively. 


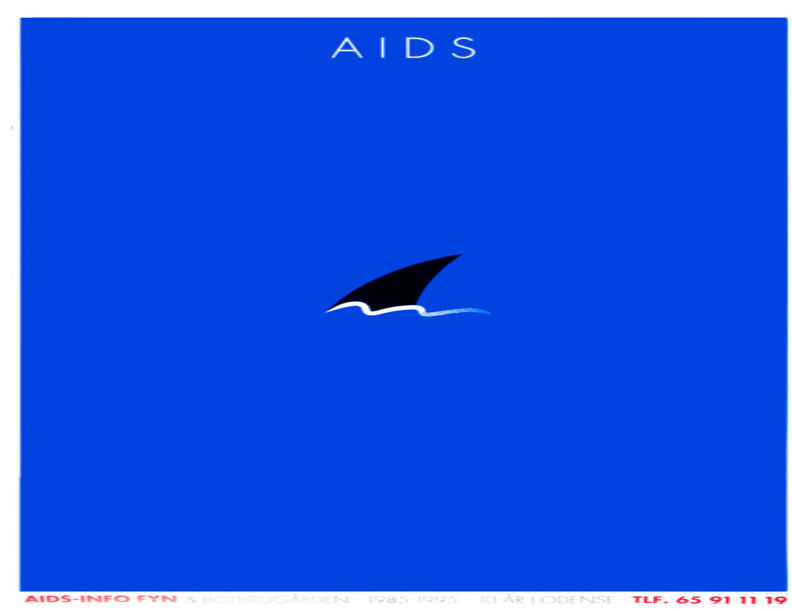

Source: http://www.graphicintervention.org

Poster 7. Denmark (1995)

Chi ha PAURA del lupo cattivo?

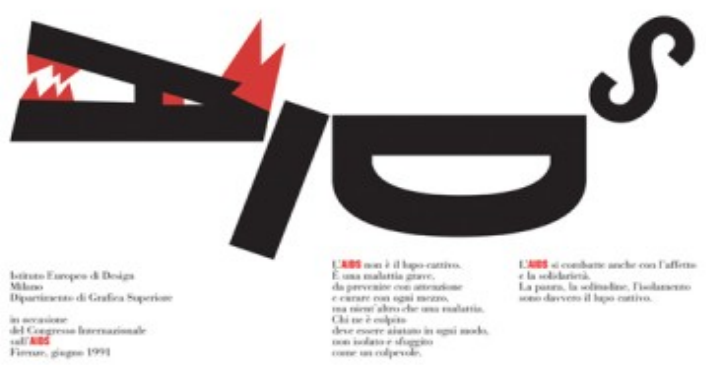

Source: http://www.graphicintervention.org

Poster 8. 1991 Italian AIDS poster: Who is afraid of theBig black wolf?

To begin with the Denmark poster (Poster 7) bearing the words AIDS written on a water mass with a shark's fin projecting from the ocean. The pictorial metaphor conceptualizes HIV/AIDS IS A LOOMING KILLER SHARK metaphor, where the shark's fin operates under PART FOR WHOLE metonymy to stand in for a killer shark. In the poster, just like in the case of snakes, sphinx, and sharks are predatory killing machines and their sharp teeth enable them to mercilessly shred their prey to pieces. From this embodied experience with sharks, it is possible to compare HIV/AIDS to sharks, especially with reference to it as a lethal killer disease. With reference to the Italian poster (Poster 8) which uses a popular children's storybook ${ }^{7}$ titled the Little Red riding hood, where Jane escaped from the jaws of the cunning big bad wolf, which killed her ailing grandmother. In many cultures, wolves like snakes and sharks have positive and negative sides, with positive aspects being their ability to hunt in packs and their excellent tracking system. However, their negative connotations seemingly outweigh their positive aspects. Said differently, wolves like sharks are predatory, cannibalistic and are

7 Wolves have also been depicted negatively in another children's storybook called the three little bears. rapacious blood thirsty beasts. Bukowich (2004) asserts that in many cultures, wolves symbolize vengeance, evil, death and are rapacious killers of innocent animals. Moreover, in Greek mythology, the image of a wolf was associated with Hecate, the goddess of darkness presupposing she epitomized evil as a witch hence a harbinger of death and destruction. Just like sharks, wolves are excellent stalkers who capitalize on the element of surprise when attacking their prey. In English, there are expressions such as $\mathrm{He}$ is such a wolf to mean that one is a womanizer, don't wolf down your food to describe unacceptable eating habits and who is afraid of the big bad wolf? and this suggests a precarious scenario. From our embodied experience with wolves, it becomes crystal clear how the wolf's rapaciousness, stalking, killing and destructives are mapped onto HIV/AIDS, hence the conceptual metaphor operating here is HIV/AIDS IS THE BIG BLACK WOLF as expressed in its linguistic metaphor Who is afraid of the big black wolf? to denote the grave nature of the HIV/AIDS pandemic.

\subsection{Other Personifications of HIV/AIDS is Death}

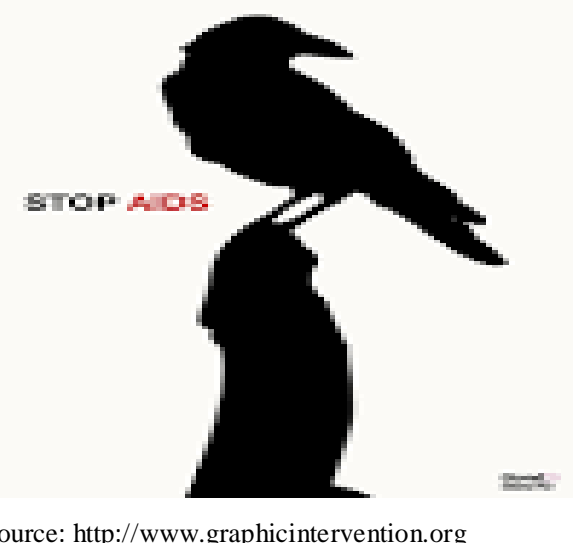

Poster 9. Hungary (2009) STOP AIDS poster

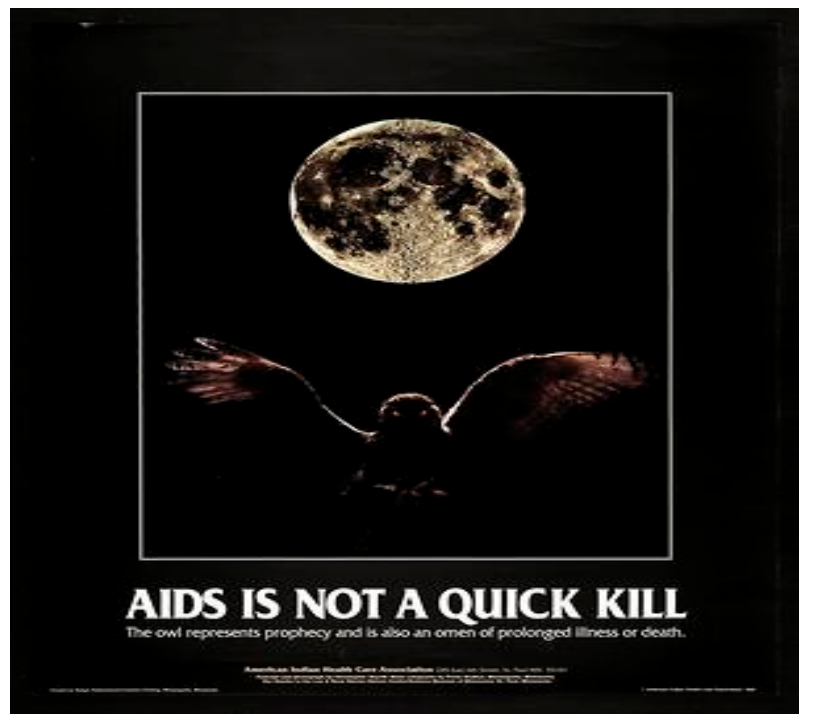

Source: http://www.aep.librochester.edu/node/41398

Poster 10. American Indian Health Care Association (1989) AIDS IS NOT A QUICK KILL 
The Hungarian poster (Poster 9) uses the image of crow pitched on top of an erect penis and it bears the message, STOP AIDS. According to Bukowick (2004) crows and wolves have a co-dependent relationship. Said differently, crows are endowed with excellent vision which they capitalize on to spot a dying or dead animal. Moreover, their calls attract other animals such as wolves or hyenas to the carcass. Crows have to depend on wolves to rip through the edible carcass. Bukowick contends that in some western societies, crows symbolize death especially when they pitch on roof tops. Moreover, they can be sighted around dead carcasses along roads, open fields and in cemeteries. Besides this, crows are negatively perceived even in some animated series such as the Maleficient, where the crow served as an emissary of Maleficient. Moreover, in a number of movies, crows are depicted as emissaries of witches. In Poster 9, HIV/AIDS is metaphorically conceptualized as HIV/AIDS IS A BLACK CROW PITCHED ON AN ERECT PENIS LACKING A CONDOM or HIV/AIDS IS A BAD OMEN. On one hand, the crow personifies death in its capacity to represent both death and destructive aspects of the pandemic. On the other hand, the erect penis lacking a condom metonymically represents the vulnerability of human sexuality in the context of unprotected sex. By contrast, poster 10 is coined in the American Indian culture; it uses pictorial images of darkness, the full moon and the owl to convey the following message AIDS IS NOT A QUICK KILL. The owl represents prophecy and is also an omen of prolonged illness or death. The poster uses HIV/AIDS IS AN OWL AS A BAD OMEN pictorial metaphor to sensitize people on the pandemic. Owls just like crows and wolves have both negative and positive dimensions, owls are viewed as symbols of wisdom, mystery and bad omen (cf. Rouhi and Raseh, 2011), a case in point is in the Persian culture the linguistic metaphor such as $\mathrm{He}$ is an owl denotes wisdom. Contrastively as seen in a comparative study on the public knowledge of owls in Costa Rica and Malawi, Enriquez and Mikkola (1997: 164) make the following observation on the negative perceptions of owls in Costa Rica and Malawi as seen in the respondents' responses.

Malawi respondent: Should an owl settle on the roof of a hut (house), it is regarded as a messenger of death. Even if it merely screams while flying near the hut/house, it is believed to be predicting some misfortunes.

Costa Rica respondent: Before my wife died, one owl was calling, several days and people kept telling me that someone will die.

Besides this, Enrique and Mikkola (1997) observe in both Costa Rica and Malawi, owls are perceived as emissaries of sorcerers ${ }^{8}$., they are associated with death and sorcery, or agents of death as captured in expressions such as a messenger of death, predicting misfortunes or owls are

8 Enrique and Mikkola (1997:164) provide a verbatim statement of a Malawian respondent who said "Owls are not real birds, they are created by witches and wizards for bewitching people" created by witches and wizards. Such statements are partly consistent with the poster's disclaimer stating that owls represents prophesy and an omen of prolonged illness of death. And just like crows, owls represent death and sorcery in some cultures and conceptual metaphors in the poster are HIV/AIDS IS NIGHT, or HIV/ AIDS IS CONCEALMENT, which are variants of DEATH IS NIGHT/DEATH IS CONCEALMENT. The same conceptual metaphor is expressed by linguistic metaphor in the poster's message reading AIDS IS NOT A QUICK KILL. This message is premised on the asymptomatic nature of the disease, where the virus gives the human body a grace period of 8 to 10 years before it becomes immuno-suppressed. The other conceptual metaphor underlying the image of owl is HIV/AIDS IS AN OWL AS A BAD OMEN/ HIV/AIDS IS AN OWL AS A SYMBOL OF DEATH OR AN INCURABLE AILMENT conceptual metaphor.

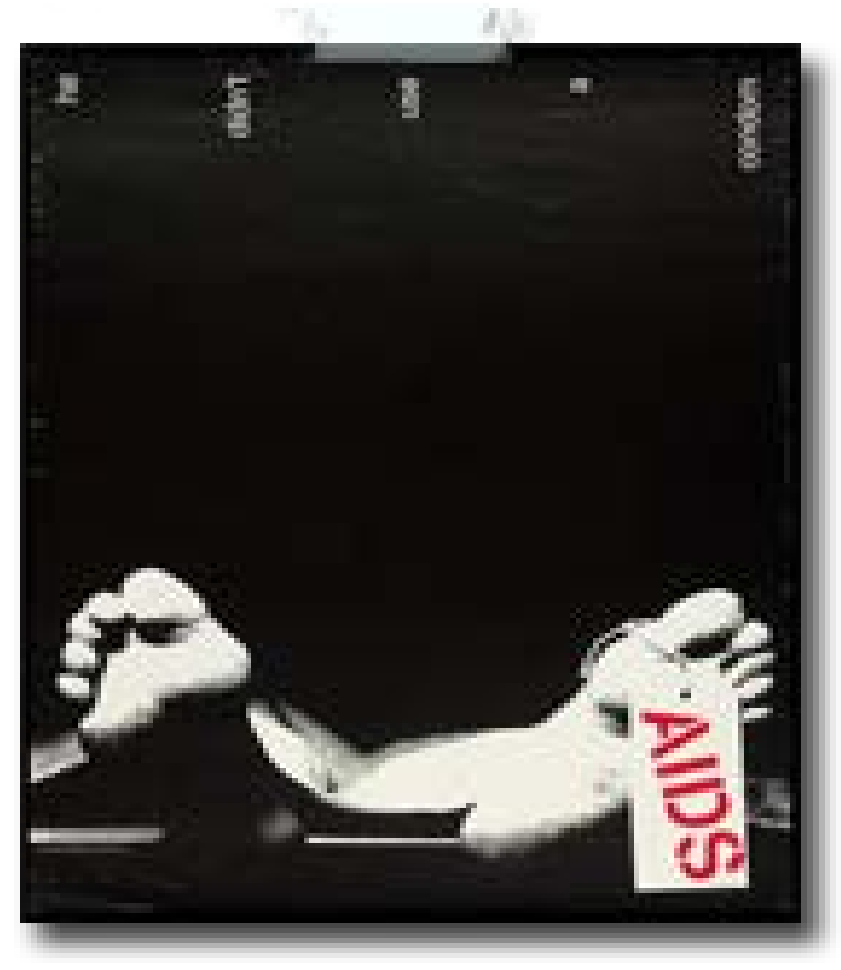

Source: http://www.pintest.com

Poster 11. American AIDS posters He did not use a condom AIDS poster

Given that crows and owls represent death, it therefore becomes imperative to explore other personifications of death such as skeletons, skulls, darkness, cemeteries and the hour glass as outlined by Lakoff and Turner (1989), Wang (2009), and Golzadeh and Pourebrahim (2013), Posters 11 to 20 present various dimensions of HIV/AIDS as death personified. First and foremost, there is need to understand that one has to die before they are placed in coffins and laid to rest. This means that there are AIDS posters coined under DEATH IS SLEEP metaphor, with the specific metaphor being DYING FROM HIV/AIDS IS ETERNAL SLEEP as shown in Posters 11 and 12, where Lakoff and Turner (1989: 19), use the analogy of the corpse on a portable autopsy table 
and a person asleep, especially inactiveness and inattentiveness. Therefore, both images of a corpse on the autopsy table in morgue with the feet bearing the tag written AIDS in red, all reinforce the message highlighting the cause of death as He didn't use a condom. Likewise, the body a famous musician Alicia Keys is in a coffin with the poster bearing the message ALICIA KEYS IS DEAD marks an online campaign meant to solicit funds or victims of HIV/AIDS by 'digitally ${ }^{9}$ ' killing celebrities as a campaign tool, such images reflect our embodied experience with the dead who are unable to function normally as they have departed to the greater beyond. Once one dies, he or she is goes home or to their final destination, and for Lakoff and Turner (1989), the departure points are many such as heaven, hell, or graveyard. In the case of posters 13 and 14, focus will be on the graveyard as a final destination for the dead under DYING FROM HIV/AIDS IS DEPARTURE TO THE FINAL DESTINATION conceptual metaphor.

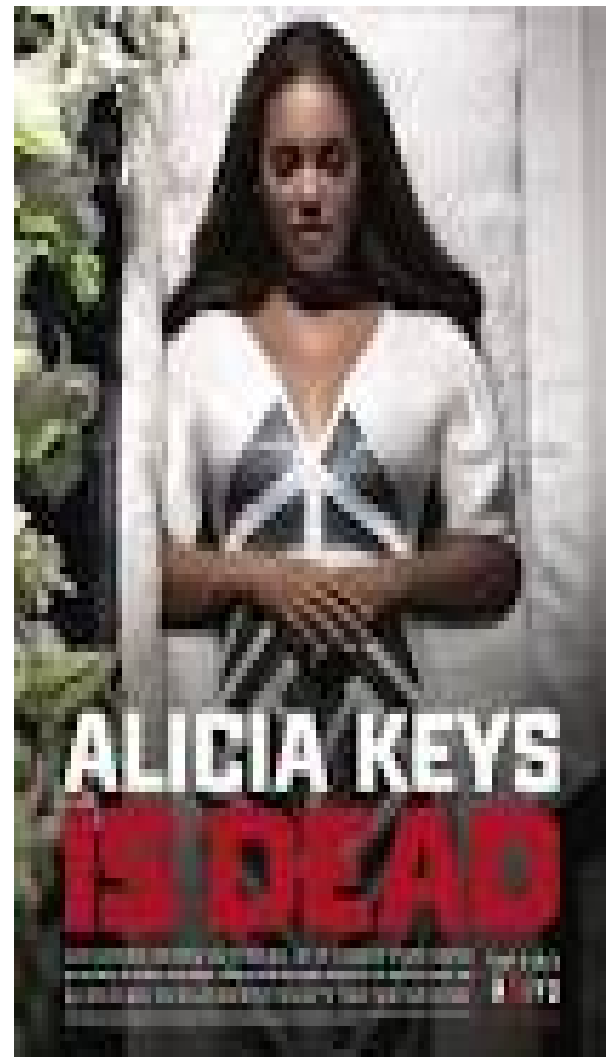

Source: http://www.celebrity.com

Poster 12. Alicia Keys in Dead AIDS poster

On one hand, Canadian poster (Poster 13) has an epitaph inscribed with the following words Le SIDA circule toujours meaning HIV/AIDS is spreading every day, which is a linguistic metaphor hosting THE SPREAD OF HIV/AIDS IS A JOURNEY conceptual metaphor. This suggests that HIV/AIDS records high mortality rates as it spreads globally. On the other hand, Poster 14 reads A bad reputation isn't all you can get from sleeping around, the poster implies that HIV/AIDS related deaths through unprotected sex is a reality. Both posters have a common denominator in that they use the graveyard pictorial metaphor with the second one having a wreath placed on the gravestone, the posters host DEATH IS GOING TO THE FINAL DESTINATION metaphor, Lakoff and Turner (1989) cite a Judeo-Christian belief in the book of Genesis 3:19, Dust thou art and unto dust shalt thou return. Here, the earth is conceptualized as the cradle of birth and also man's burial place. Lakoff and Turner argue that the grave can be superimposed to the image of the house, where the roof of the house corresponds to the bulge of the earth, the cornice of the roof corresponds to the gravestone, with the interior of the house being the earth or the coffin and the latter rots to become part and parcel of the earth. In poster 13, the image of the gravestone, and a statue of a lady on top of the epitaph are all regarded as personifications of death. Moreover, the epitaph normally contains the deceased's names and details on his date of birth and death. In this case, prominence is given to HIV/AIDS as an agent of death and this is reflected in its message stating Le SIDA circule toujours (HIV/AIDS is continuously spreading) and also in the message $A$ bad reputation isn't all you get from sleeping around. Both posters strongly suggest that death is inevitable in the context of HIV/AIDS and both posters metonymically represent HIV/AIDS related deaths using the graveyard pictorial metaphor. Closely related to the concept of the grave or earth is also the hourglass metaphor as shown in Poster 15

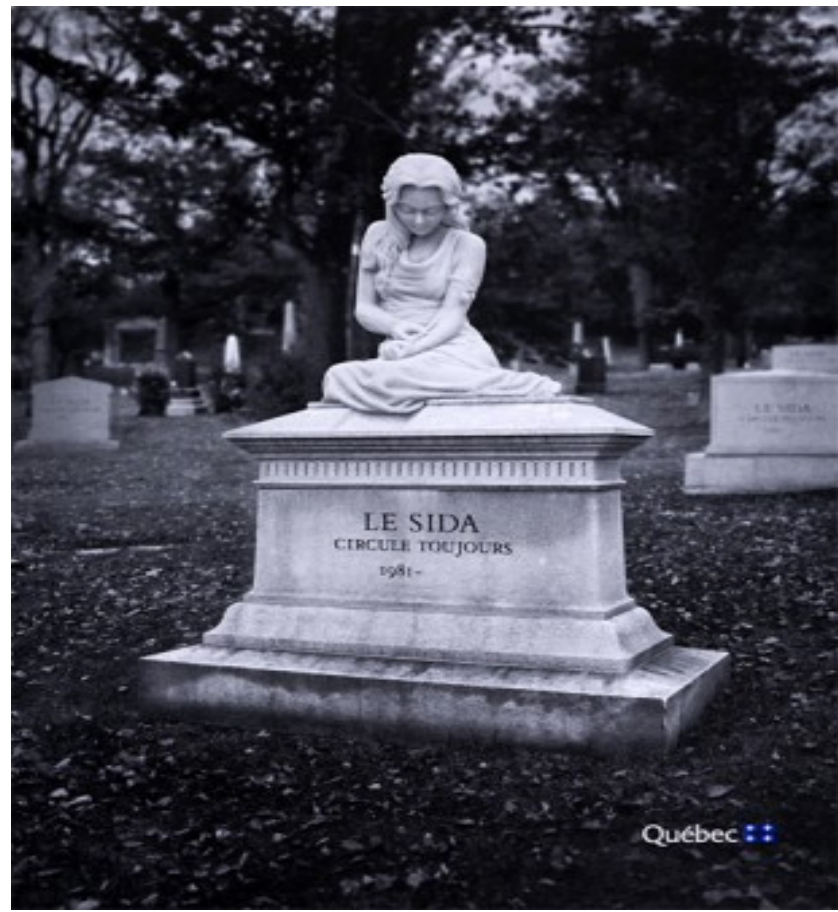

Source: http:www.graphicintervention.com

Poster 13. 1981 Canadian AIDS poster 


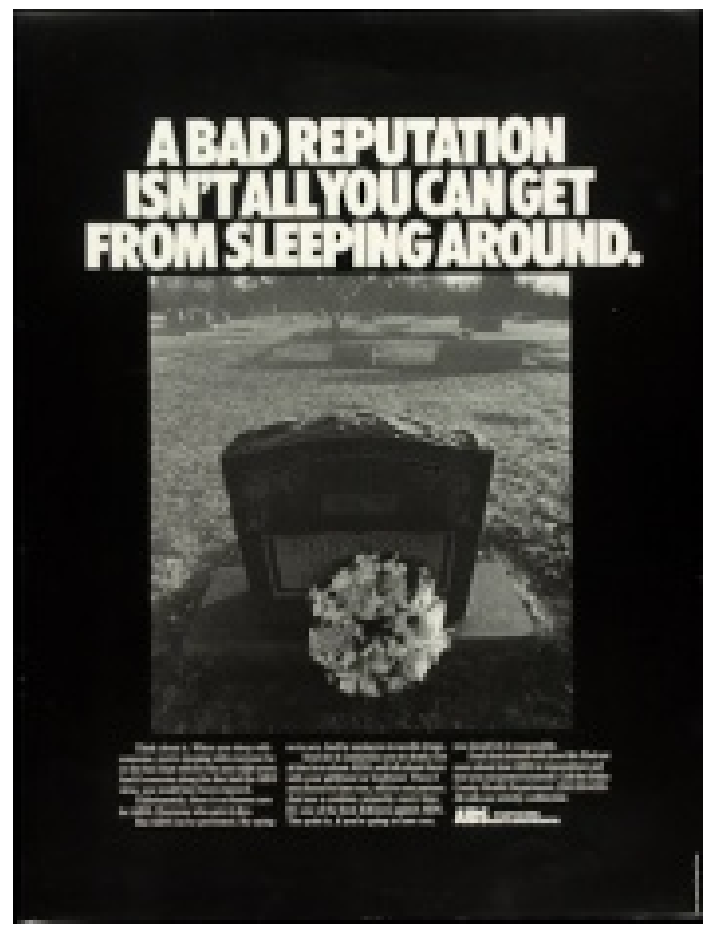

Source: http://smithsonianmag.com

Poster 14. 1980 American AIDS poster

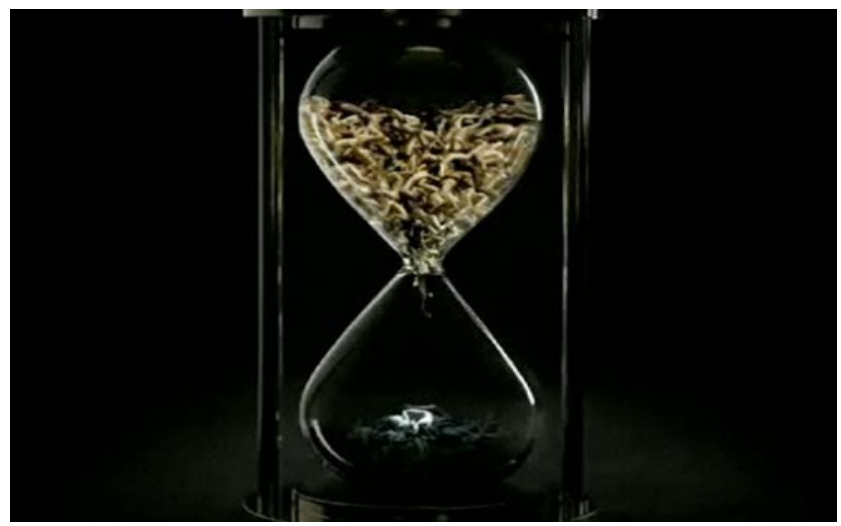

Source: http://www.condomunity.com/

Poster 15. 2007 France AIDS poster

According to an article written by antonymous author titled Death as Metaphor, the grains of sand that drain away in an hourglass fuses time, life and death using various conceptual metaphors such as TIME IS A THIEF, TIME IS A CHANGER, LIFE IS PRECIOUS and DYING IS RUNNING OUT OF TIME (cf. Lakoff and Turner, 1989). According to the anonymous author life is represented by time, and with the passage of time, changes are bound to occur as one ages, eventually time runs out and death is inevitable. In the context of the above poster by Sidaction is accompanied by the message reading Dans le monde, une personne meurt du sida tout les 10 secondes. Protegez vous. (Every ten seconds, someone dies of AIDS in the world. Protect yourself). The hour glass metaphor uses images of nude men and women engaged in an unprotected sex orgy and just like sand that wastes away in an hour glass, such people risk contracting HIV/AIDS. Said differently, promiscuous seropositive persons are people living on borrowed time, for seropositive persons TIME IS A THIEF as it robs them of their good health and eventually their precious lives. Moreover, in the course of time, the opportunistic infections introduce changes that weaken the human body and eventually the person dies. The hourglass pictorial metaphor also hosts PROMISCUITY IN THE ERA OF THE PANDEMIC IS LIVING ON BORROWED TIME metaphor.

Once one dies, naturally the body is interred and eventually it decomposes with a skeleton remaining in the coffin. There are some HIV/AIDS campaign posters that use skeletons and skulls, to personify HIV/AIDS related deaths as shown in Posters16, 17, 18 and 19. The first poster Kenyan (Poster 16) reading what you see in not what you get, uses the LIFETIME IS DAY metaphor with particular reference to DEATH IS NIGHT and NIGHT IS CONCEALMENT metaphor, whereby from a far and under the cover of darkness is a male client who is approaching a seropositive commercial sex worker. Here, HIV/AIDS is personified as a skeleton mounted on the human body of the commercial sex worker. Apparently, this is evident to the audience but not the man in the poster. In this context, HIV/AIDS IS DEATH PERSONIFIED IN THE IMAGE OF A SKELETON metaphor features here. Poster 18 was used in France to sensitize the gay community on the dangers of unprotected sex in its message protegez-vous (protect yourselves). The image uses explicit imagery of nude women engaged in an orgy of unprotected sex. Interestingly, their positioning assumes the shape of the skull. The skull metonymically represents the human skeleton, as such the poster also propagates HIV/AIDS IS DEATH PERSONIFIED IN THE IMAGE OF THE SKULL and also DARKNESS IS DEATH conceptual metaphor is employed in the background of this poster. Besides the skull, skeleton's phalanges have been extensively used in Russia to metonymically present the skeleton particularly in contexts where HIV/AIDS is spread through syringes used by injecting devices users (IDUs) such as drug addicts. Here, poster 18 used in Australia, reads AIDS, sharing needles is just asking for it, it uses the EVENTS ARE ACTIONS metaphor, whereby needle sharing is the norm among drug addicts, and transmission of HIV/AIDS is caused by an agent who is personified metonymically using Grim reaper's phalanges or image of the phalanges passing a contaminated syringe to another unsuspecting individual who has stretched his hand to receive the syringe. The Ukraine poster (Poster 19) shows the phalanges of the hand which has been injected by a contaminated needle and with blood oozing from the phalanges. This contradicts reality since skeletons are incapable of bleeding. The other possible metaphor operating here is SHARING CONTAMINATED NEEDLES IS REQUESTING FOR HIV/AIDS FROM GRIM REAPER or SHARING CONTAMINATED NEEDLES IS ASKING FOR DEATH. 


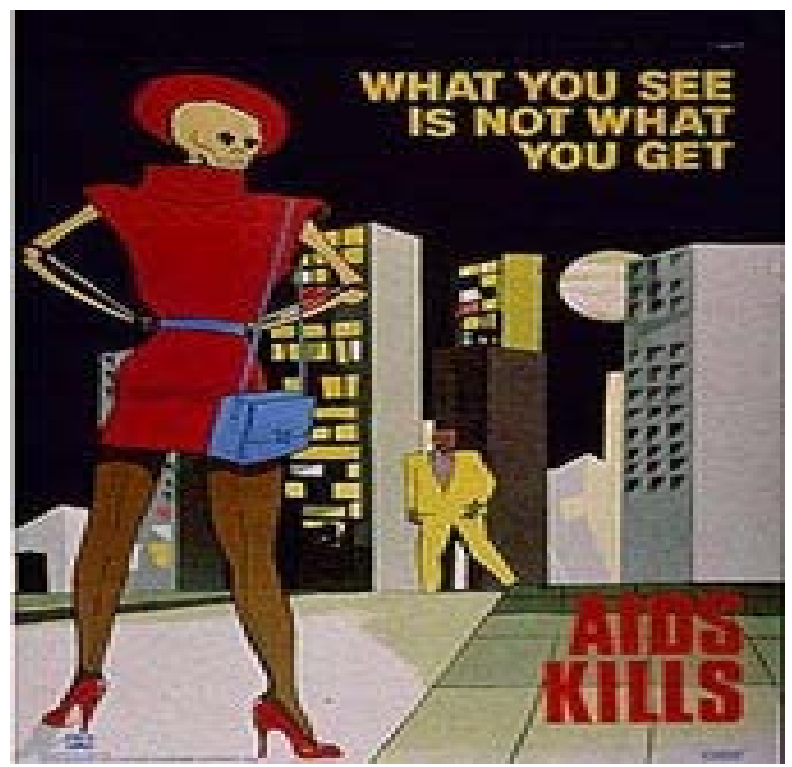

Source: http://www.m-mc.org/mmc

Poster 16. 1989 Kenyan AIDS poster

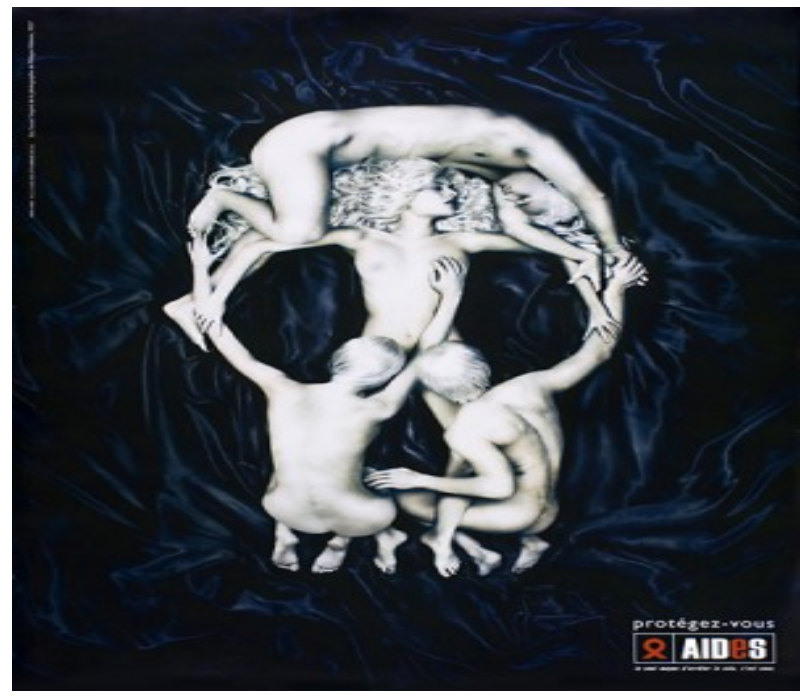

Source: http//www.graphicintervention.org

Poster 17. 2003 France AIDS poster: Protect Yourself.

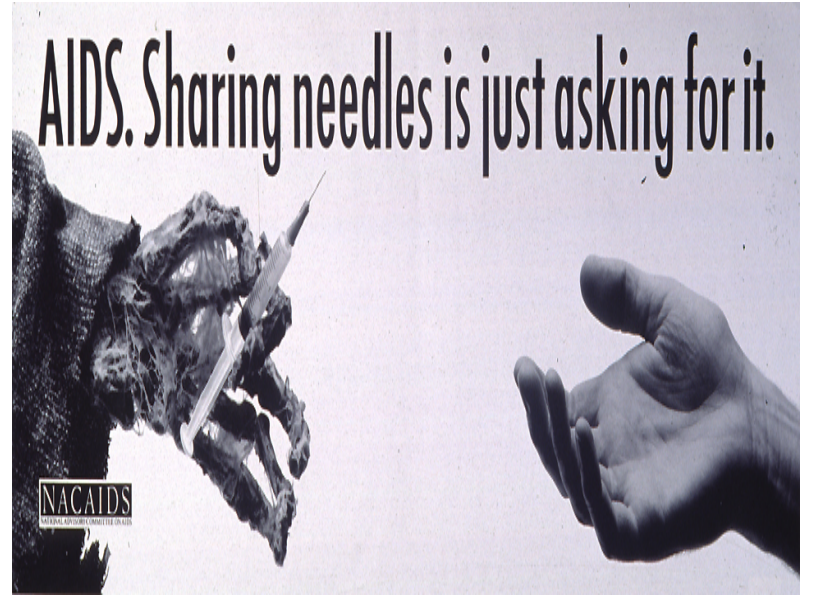

Source: http://www/m.nih.gov/exhibition//visualculture/target/html Poster 18. (1988) National Advisory Committee on AIDS in Australia

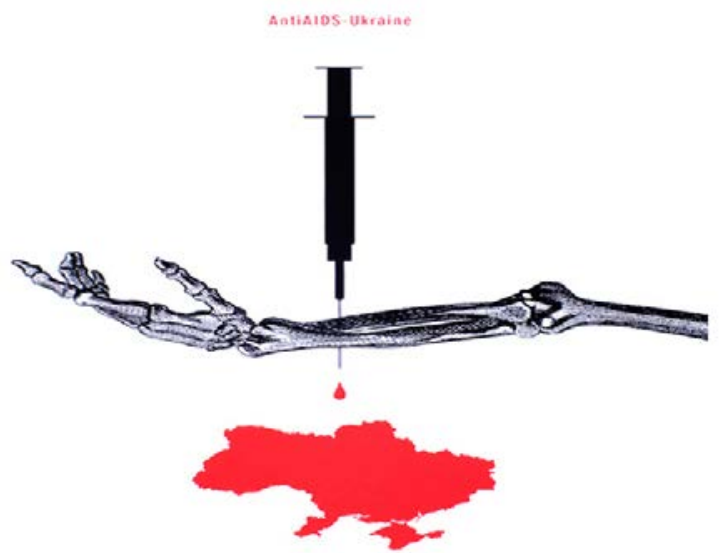

Ximenosion

Source: http://www.graphicintervention.org

Poster 19. 2007 AntiAIDS Ukraine poster

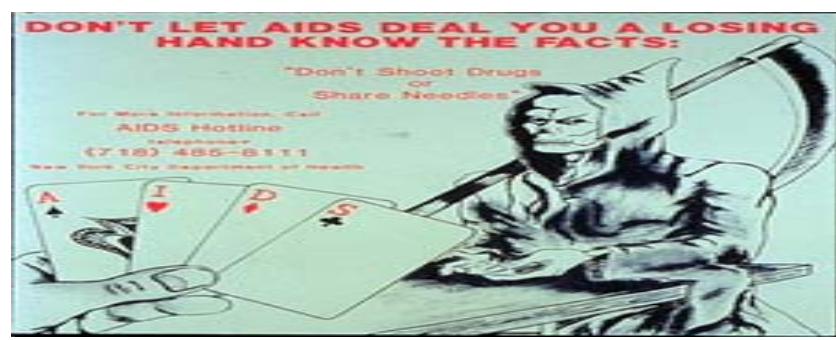

Source: http://www.mc.org/mmc

Poster 20. New York City department of Health AIDS Campaign poster

The New York City campaign poster (Poster 20) predominantly uses STAYING ALIVE IS A CONTEST conceptual metaphor at the generic level. The poster shows a hand that metonymically represents an uninfected person holding cards that spell AIDS that have been dealt out by Grim reaper aimed with his scythe. The image echoes an earlier observation by Wang (2009:44) where Block engages death or grim reaper a game of chess in order to delay death. In Cognitive Linguistics, Grim reaper personifies death as cited in Lakoff and Turner (1989) and Magonya, (2012). The poster bears the message that is double-highlighted since it is written both in red and in capital letters DON'T LET AIDS DEAL YOU A LOSING HAND KNOW THE FACTS. Don't shoot drugs or Share needles. The poster warns drug users against giving HIV/AIDS an upper hand either by shooting drugs or sharing needles. The term deal is associated with card games where the action of dishing out cards is referred to as dealing. In the poster, needle sharing or shooting drugs exposes one to the risk of infections and is metaphorically synonymous to letting Grim reaper or HIV/AIDS deal out cards. The conceptual metaphors in the poster are HIV/AIDS IS GRIM REAPER, FIGHTING HIV/AIDS IS PLAYING A GAME OF CARDS WITH GRIM REAPER, DEALING A LOSING HAND IN THE FIGHT AGAINST HIV/AIDS IS SHOOTING DRUGS or SHARING NEEDLES SHOOTING DRUGS IS INJECTING ONESELF WITH A NEEDLE metaphors. Finally, also within the context of 
graveyards and death is conceptualized as silence as realized in the English linguistic metaphor as silent as the grave which contrasts its Kiswahili counterpart that says Kimya kama maji ya mtungi (as quiet as the water in a pot). In the context of HIV /AIDS, silence and AIDS- related stigma are interwoven as silence promotes the culture of living in denial which apparently is counterproductive in the fight against HIV/AIDS. Behavior change communicators have also explored usage of SILENCE ABOUT HIV/AIDS IS DEATH conceptual metaphor that is placed on the red ribbon to symbolize the fight against the epidemic. The message is meant to defuse the HIV/AIDS stigma as shown in the following AIDS poster. The poster sensitizes populations against being silent about the dangers of HIV/AIDS and it advocates for people being positive about HIV/AIDS by accepting, loving, accommodating, embracing seropositive persons and advocating for their rights. This is because silence about HIV/AIDS is equated to death.

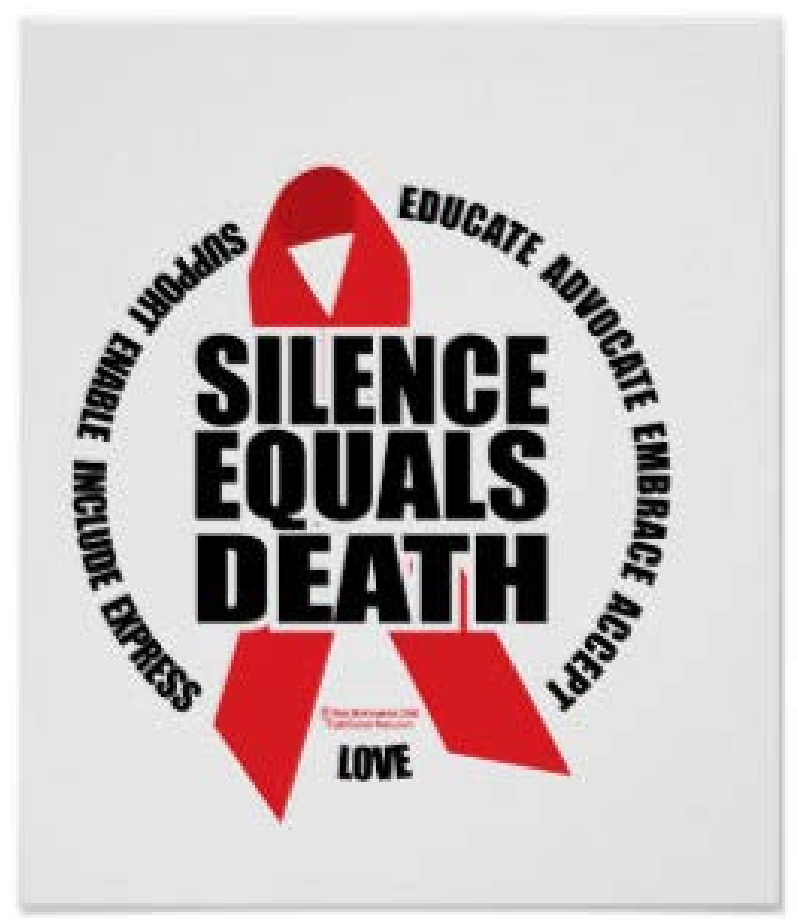

Source: http://www.zazzle.co.uk/hiv_aids_silence_equals_death_poster (Poster 21)

From the foregoing, it is clear that even death personified is varied, some cultures would use skeletons, others would use sections of the human skeleton such as the skull, the phalanges or even the image of grim reaper with his scythe and also silence. All these types of personifications are meant to convey their varied conceptualizations of the personifications of death in HIV/AIDS posters.

\section{Conclusions}

The analyzed posters affirm the existence of cross-cultural variations, first and foremost, the presence of congruent metaphors is realized in metaphors such as HIV/AIDS IS A
FEROCIOUS MONSTER OR BEAST conceptual metaphor at the generic level has various realizations in different pictorial metaphors of various cultures at the specific level, for instance, HIV/AIDS IS A FEROCIOUS FEMALE SPHINX, HIV/AIDS IS A LETHAL SNAKE, (For this metaphor there are variations in the types of snakes at the specific level of the pictorial metaphors) HIV/AIDS IS A KILLER SHARK, HIV/AIDS IS THE BIG BLACK WOLF, HIV/AIDS IS A BAD OMEN, or HIV/AIDS IS DEATH PERSONIFIED. There are variations in terms of HIV /AIDS IS DEATH PERSONIFIED IN THE IMAGE OF A SKELETON, HIV/AIDS IS DEATH PERSONIFIED IN THE IMAGE OF THE SKULL, SILENCE ABOUT HIV/AIDS IS DEATH, STAYING ALIVE IS A CONTEST IN A GAME OF CARD WITH GRIM REAPER. As pertaining to the range of the target domain, besides the mentioned conceptual metaphors, there other target domains for example DYING FROM HIV/AIDS IS ETERNAL REST has the pictorial metaphor of the corpse of a seropositive person on a portable autopsy table with a tag written AIDS and also another image of Alicia Keys placed inside a coffin. Another example is under DYING FROM HIV/AIDS IS GOING TO ONES FINAL DESTINATION. Here, target domains are varied for instance the gravestone, epitaph, wreath, skeleton, skull, phalanges, darkness, the hourglass and silence provide target domains for HIV/ AIDS IS DEATH conceptual metaphors. On the concept of cultural preference, if we take the case of HIV/AIDS IS A BAD OMEN conceptual metaphor, there is a cultural preference whereby in some societies, HIV/AIDS IS A BLACK CROW PITCHED ON AN ERECT PENIS WITHOUT A CONDOM, or HIV /AIDS IS AN OWL AS A BAD OMEN. The same can be said about HIV/AIDS IS A LETHAL SNAKE as a generic metaphor or near universal metaphor captured in its usage in various countries such as Brazil, Kenya, Netherlands and even in South Africa, there are culture specific conceptualizations of lethal snakes, for some cultures it is the python, a monstrous green snake, black mamba or even a green snake can serve as potential target domain. The same can be said about ferocious creatures whereby in the Netherlands AIDS poster, HIV/AIDS IS A LOOMING KILLER SHARK conceptual metaphor is used whereas the Italian poster uses HIV/AIDS IS THE BIG BAD WOLF conceptual metaphor. Finally, on the question of unique metaphor, the Russian HIV/AIDS in Poster 1 has HIV/AIDS IS A FEROCIOUS FEMALE SPHINX culturally unique pictorial metaphor rooted in the Greek culture. The same can be said about the hourglass pictorial metaphor which is a European concept of showing TIME IS A CHANGER metaphor and how the passage of time can eventually lead to one's death, especially with reference to HIV /AIDS.

\section{Metaphors of Time}

TIME IS A CHANGER-Do not worry things will change 
with time (own example)

TIME IS A THIEF: Time has stolen my youth (Lakoff and Turner (1989:7), from Milton' Sonnet

TIME MOVES/ TIME IS A RUNNER: Time is moving fast (Lakoff and Turmer, 1989)

TIME IS A PURSUER: I am being pursued with time.

TIME IS A REAPER/ TIME IS A DEVOURER: Time is the devourer of everything (Lakoff and Turner, 1989:42)

TIME IS AN EVALUATOR: Time heals all wounds (Own example)

EVENTS ARE ACTIONS Events conspired to delay the game (Lakoff and Turner, 1989)

STATES ARE LOCATION:

LIFETIME IS A YEAR-Spring-Youth, Summer-Maturity, Autumn-Old Age, Winter-Death

LIFETIME IS A DAY: Dawn (birth), maturity (noon), old age (twilight), death (sunset)

\section{Life Metaphors}

LIFE IS A JOURNEY: Look how far we have come (Lakoff and Turner, 1989)

LIFE IS A PRECIOUS POSSESSION I regret but I have one life to give for my family

LIFE IS UP: He is up and about. (Lakoff and Turner, 1989)

LIFE IS A PLAY: It is curtains for him (Lakoff and Turner, 1989)

LIFE IS A FLAME: Early flaming up (heat of the youth), steady flame -middle age, embers-diminished vitality of old age, ashes: Consequences of living, cold ashes-death (Lakoff and Turner, 1989: 31)

LIFE IS FIRE/HEAT/LIGHT: She is burning with youthful zeal (own example)

LIFE IS LIGHT (LIGHT IS A SUBSTANCE THAT CAN

BE TAKEN AWAY) I am the light of the world

LIFE IS A CANDLE: Taya ma dala no osim nikech Tom otho (The latern of that homestead has been extinguished with Tom's death) (Own example from the Luo tribe)

LIFE IS A FLUID IN THE BODY: She is bursting with life (Lakoff and Turner, 1989)

LIFE IS A BURDEN/LIFE IS A BONDAGE: Cast your burdens unto Jesus, for he cares for you (A religious song Cast Your Burdens)

BIRTH IS ARRIVAL: After three hours of labour, eventually her baby came at exactly 6.00am in the morning. (own example)

LIFE IS BEING PRESENT HERE: He is still with us (Lakoff and Turner, 1987)

\section{Death Metaphors}

DEATH IS DEPARTURE: He has left us and has gone to be with his maker (own example)

DEATH IS LOSS OF FLUID IN THE BODY: His still body looked drained and lifeless (own example)

DEATH IS COLD: His cold lifeless bold remained motionless in the morgue (own example)

DEATH IS DOWN: A fallen hero will be buried tomorrow in Belgium (own example)

DEATH IS ETERNAL /DEATH IS THE END He has finished his journey on earth (Solhein, 2014, Al-Meshhedany \&Al- Sammerai, 2010)

DEATH IS THE LAST HOUR: In his last dying minutes (Solhein, 2014)

DEATH IS SLEEP/REST: Rest in Eternal peace. (Fernández, 2006)

DEATH IS DELIVERANCE: Death broke at once the vital chain and freed his soul (Lakoff and Turner, 1987:24)

DEATH IS NIGHT/NIGHT IS CONCEALMENT: Sunrise: $20^{\text {th }}$ January 1979 Sunset : $14^{\text {th }}$ February 2016 ( Daily Nation, Obituary Page)

DEATH IS A REAPER: Death took him away (own example)

DYING IS LOSING A CONTEST AGAINST AN ADVERSARY/DEATH IS SURRENDER: He could not escape the jaws of death (own example)

DEATH IS DEPARTURE He has gone to be with his maker (own example)

PEOPLE ARE PLANTS She is a late bloomer, young sprout-early stages of life, in full bloom -mature, wither away (approaching death) (Lakoff and Turner, 1987: 6)

DEATH IS LOSS OF A PRECIOUS POSSESSION: He lost his life in a fatal road accident. (Own example)

\section{REFERENCES}

[1] Al-Meshhedany, A., $\mathrm{H}$ and Al-Sammerai, (2010). Facing Finality: Cognitive and Cultural Studies on Death and Dying in Arabic Culture. English Language Teaching, Vol. 3, No. 1, March 2010.

[2] Anjomsha, L. and Sadighi, F. (2015) The Comparison of Connotative meaning in Animal words between English and Persian Expressions and their translations. International Journal in Studies in English language and literature. Volume 3, Issue 2, pp 66-77

[3] Baloyi, L. and Makobe-Rabothata (2014) The African Conception of Death: A cultural implication. In Jackson, L., Meiring, D., Van de Vijver., F., Idemudia, E., and Gabrenya, W. K. (Eds) towards sustainable development through nurturing diversity. Selected Papers from the $21^{\text {st }}$ Congress of International Association for Cross Cultural Psychology. Melbourne, FL: International Association for Cultural Psychology.

[4] Bukowich, K. E. (2004) Truth and Symbolism: Mythological perspectives of the wolf and the crow. Boston College Electronic Dissertation website https://dlib.bc.edu/islandora/object/bc-ir:102331/datastream/P DF/view. Consulted on $10^{\text {th }}$ October 2016

[5] Byock, I. (2002). The Meaning and Value of Death. Journal of 
Pallative Medicine. Volume 5, Number 2.

[6] Enriquez, P. and Mikkola, H. (1997). Comparative Study of Public Owl Knowledge in Costa Rica, Central America and Malawi Africa. In Duncan, J., Johnson, D., and Nicholls, H., (Eds). Biology and Conversation of Owls of the Northern Hemisphere. USDA Forest, General Technical Report NC-190. Second Owl International Symposium. Winnipeg, Manitoba, Canada.pp. 160-167

[7] Fernández, C. E (2006). The Language of Death: Euphemism and Conceptual Metaphorization in Victorian Obituaries. Sky Journal of Linguistics 19, pp. 101-130.

[8] Fernández, C. E (2007). Linguistic Devices Coping with Death in Victorian Obituaries. Revista Alicantia de Estudios Ingleses 20 (2007): 7-21

[9] De Waal, A. (2006). AIDS and power, why there is no political crisis yet. Cape Town: Zed books and The African International Institute.

[10] De Saussure, F. (2015). A course in General Linguistics. London: Mc Graw Hill Book Company.

[11] Gibbs, R. (1994). Poetics of the Mind: Figurative Thought Language and Understanding. Cambridge: Cambridge University Press.

[12] Gire, J. (2014). How Death imitates life: cultural influences on conceptions of Death and Dying. Online readings in Psychology and Culture, 6 (2). http://dx.doi.org/10.9707/2307-09191120.

[13] Golzadeh, F. A and Pourebrahim, S. (2014). Death Metaphor in Religious Texts: A Cognitive Semantics Approach. International Journal of Humanities, Volume 20 (4):(61-78)

[14] Kövesces, Z. (2005). Metaphor in Culture. Universality and Variation. Cambridge: Cambridge University Press.

[15] Kövesces, Z. (2006). Language, Mind and Culture. A Practical Introduction. Oxford: Oxford University Press.

[16] Kövesces, Z. (2010). Metaphor. A Practical Introduction. Oxford: Oxford University Press

[17] Lakoff, G.and Johnson, M. (1980). Metaphors we live by. Chicago and London: The University of Chicago Press.

[18] Lakoff, G., and Turner, M. (1989). More than cool reason. A field guide to poetic metaphor. Chicago: University of Chicago Press.

[19] Lakoff, G. (2008). The Neural Theory of Metaphor. In Gibbs,
R. (Ed) The Cambridge handbook of Metaphor and Thought. Cambridge: Cambridge University Press.

[20] Magonya, L. and Oloo, P. (2012). Experience is the best teacher: A cognitive Approach to some African mental representations and implicit assumptions on AIDS and other Diseases. US-China Foreign Language. Volume, 10, Number, 6.

[21] Magonya, L. and Oloo, P. (2015). What gets mapped onto what in the sex is a football game metaphor in Kenyan HIV/AIDS campaign posters? In Linguistics and Literature Studies, Volume 3 (4),pp. 148-161

[22] Moore, C., C and Williamson, J. (2003). The universal fear of death and the cultural response. In Bryant, C. D (Ed). Handbook of Death and Dying. Thousand Oaks, CA. Sage publishers. pp 3-14

[23] Moreno, C. F. (1998). Time, life and death metaphors in Shakespeare's Sonnets: The Lakoffian Approach to Poetics. RESLA 13 (1998-99), pp. 287-304

[24] Nyakoe, D., Matu, P. and Ongarora, D. (2012). Conceptualization of 'Death is a Journey' and 'Death as Rest' in Ekegusii Euphemism. Theory and Practice in Language Studies, Volume 2, Number 7, pp 1452-1457,

[25] Psomadakis, C. (2007.) Mapping Metaphors in Modern Greek: Life is a journey. Fifth Cambridge Postgraduate conference. Cambridge Institute of Language Research: Cambridge. Pp. 221-228. URL

Http://www.ling.cam.ac.uk./camling/Manuscript/CamLing20 07_Psomadakis.pdf

[26] Roman, L. and Roman, N. (2010). Encyclopedia of Greek and Roman Mythology. Infrobase Publishing: New York.

[27] Sabatier, R. (1988). Blaming Others: Prejudice and race worldwide AIDS. London: The Panos Institute.

[28] Sherman, J. (2008). Storytelling: An Encyclopedia of Mythology and Folklore. New York: Myron, E. Sharpe

[29] Sontag, S. (1988) AIDS and its metaphors. London: Penguin Group.

[30] Trinity University (2016) Death as Metaphor. Http

[31] Wang, M., D., (2009) Ingmar Bergman's Appropriations of the Images of Death in the Seventh Seal. Website https://www.scribd.com/document/134642372/Denise-WangIngmar-Bergman-s-Appropriations-of-the-Images-of-Death-i n-The-Seventh-Seal. URL consulted on 20th January 2017 